\title{
Aspectos de la traducción al español del lexema polaco trzeba
}

Palabras clave: traducción — equivalentes — contraste — expresión de la necesidad

- polaco y español.

\section{Introducción}

A la hora de expresar obligación o necesidad de realizar una acción, el hablante del idioma polaco dispone de medios léxicos y gramaticales. Tiene la opción de emplear ciertos verbos considerados modales como musieć (tener que), powinien (deber) para, por ejemplo, ordenar algo de forma personal. Asimismo, el hablante dispone de expresiones impersonales formadas por lexemas trzeba (hay que), należy (es preciso, es necesario) o powinno sie (hay que, se debe), acompañados de infinitivo. Entre otros recursos que ofrece el idioma polaco están los medios gramaticales, es decir, el tiempo presente o futuro de indicativo en los que se emplean verbos de cualquier clase (es decir, no solamente los modales obligativos): Zaczynamy! (Empezamos), Pójdziesz do apteki i kupisz mi aspirynę (Irás a la farmacia y me comprarás aspirina).

Al principio, nos hemos planteado la idea de realizar una investigación conjunta de las expresiones impersonales trzeba, należy, powinno się para revelar las posibles diferencias reflejadas en castellano, pero en vista de que tal examen sobrepasa de manera considerable los límites de un artículo, lo hacemos de forma puntual centrándonos en el examen del lexema trzeba. Nos interesa comprobar su funcionamiento y sus equivalencias en la traducción.

En nuestro estudio, que pretende tener un enfoque contrastivo, la lengua de partida será el polaco y la lengua meta, el español; por tanto, pretendemos realizar un trabajo de carácter unidireccional, basado en textos escritos en polaco. Al principio, vamos a describir las características gramaticales y los valores semánticos del lexema seleccionado. A continuación, queremos ver qué 
equivalentes del lexema trzeba proponen los diccionarios bilingües. Luego, vamos a comentar cuáles son los homólogos españoles del vocablo elegido en las traducciones (intentaremos comprobar, por ejemplo, si las traducciones se corresponden con las entradas en los diccionarios bilingües, si mantienen el mismo valor de obligación o necesidad y, en suma, qué cambios, gramaticales o semánticos, se producen en el texto de llegada). El método que proponemos se puede denominar el método comparativo de aproximación traductológica y en la investigación nos basamos en los principios del estructuralismo y de la gramática descriptiva. La metodología de investigación basada en las traducciones es, en realidad, bastante sencilla (aunque la misma detección de los ejemplos requiere su tiempo), y consiste en la búsqueda de la unidad elegida, la detección de sus equivalentes en las traducciones y la comparación de las unidades en ambos idiomas. Las oraciones en la versión original (se considera la oración un contexto mínimo) y sus traslaciones forman el corpus de estudio del que ofrecemos los ejemplos más representativos.

A fin de que nuestro examen resultase completo, hemos elegido cuatro libros de escritores polacos y sus respectivas versiones en castellano. El primero, de Stanisław Lem (de 1961) es Pamiętnik znaleziony w wannie (Memorias encontradas en una bañera); fue traducido por Jadwiga Maurizio y se publicó en Barcelona en 1977. Otro libro es de Tadeusz Konwicki (1979), Mała apokalipsa (Un pequeño apocalipsis), traducido al castellano por Bożena Zaboklicka y Francesc Miravitlles. Salió en España en el año 1987. Nuestra siguiente fuente del corpus la constituye una novela de Andrzej Szczypiorski, Początek, que se publicó en 1986 en París. Hemos examinado su traducción al español realizada en el año 2002 por Pilar Gil Cánovas bajo el título La bella señora Seidenman: el comienzo. De la novelística más reciente hemos elegido Koniec świata w Breslau (Fin del mundo en Breslau) de Marek Krajewski, de 2003. De su traducción se encargó Fernando Otero Macías (2008).

\section{El lexema trzeba. Sus peculiaridades gramaticales y semánticas}

Conforme al diccionario de la lengua polaca ${ }^{1}$, el lexema trzeba tiene dos acepciones. La primera es de "powinno się, należy, wypada", lo cual se puede traducir como hay que, es preciso, conviene. Como ejemplos se citan frases Trzeba być uczciwym (Hay que ser honesto), Trzeba dodać, przyznać, że... (Hay que añadir, admitir que...). También aparecen expresiones fijas como jak trzeba, documentada con el ejemplo postępować jak trzeba (actuar de manera conveniente, como debe ser). Entre los otros fraseologismos el diccionario registra trzeba być jakimś, kimś (p. ej. bardzo odważnym), żeby... y

\footnotetext{
${ }^{1}$ M. Szymczak (ed.), Stownik języka polskiego PWN, Warszawa, PWN, 1998, t. 3, p. 504.
} 
Trzeba ci con el ejemplo de Trzeba ci wiedzieć, że... (es necesario que sepas, deberías saber que...). Excepto la expresión fija jak trzeba, el lexema se combina con el infinitivo.

En la segunda acepción se explica que trzeba denota "coś jest potrzebne, konieczne, nieodzowne dla kogoś, ktoś potrzebuje czegoś” (algo es necesario, preciso, imprescindible para alguien, alguien necesita algo). Se ofrecen, entre otros, los siguientes ejemplos: Trzeba natychmiast dać mu lekarstwo (Hay que darle el medicamento inmediatamente) y un caso en el tiempo pasado Trzeba byto iść dalej (Había que ir más lejos, aunque según el contexto podría interpretarse como un reproche de tipo Haber ido más lejos). En los usos citados, trzeba requiere un infinitivo. Asimismo, puede emplearse sin presencia de un verbo como en la pregunta Trzeba ci pieniędzy? que tiene el valor de ¿Necesitas dinero? o Trzeba czasu, aby to zrozumieć (Se necesita tiempo para comprenderlo). En polaco existe la expresión Nie trzeba que funciona como una forma de contestación a una propuesta de ayuda (Pomóc ci? Nie trzeba¿Te ayudo? No hace falta).

Mirosław Bańko en Inny słownik języka polskiego (2000) presenta una visión un poco diferente de este lexema (de hecho, la traducción del título es Otro diccionario de polaco). Entre los nueve valores de trzeba nos limitamos a tres. Para no cansar al lector con largas citas de tipo lexicográfico, reducimos las explicaciones de este diccionario a lo siguiente: trzeba denota que el hecho de hacer algo está provocado por alguna necesidad (Czy warto to czytać? Nie tylko warto, ale nawet trzeba...), señala condiciones para que se pueda realizar algo (Trzeba mieć dużo zdrowia, aby wytrzymać taka podróż) y sirve para expresar opiniones consideradas necesarias (trzeba wspomnieć, przyznać trzeba). Luego, el diccionario incluye usos nominales. Por lo que se refiere al uso de trzeba combinado con infinitivo, en nuestro estudio optamos por el enfoque de Bańko y no hacemos distinciones entre los valores de este vocablo puesto que, en realidad, siempre denota alguna necesidad de realizar un hecho, sea impuesta por alguna autoridad, sea referida a las circunstancias externas.

Por lo que se refiere a los valores gramaticales, cabe señalar que trzeba es un lexema peculiar. Tiene carácter verbal, pero se conjuga solamente en la tercera persona de número singular. Dispone de tan solo una forma simple (trzeba en presente), mientras que las otras tienen carácter analítico: trzeba będzie (futuro), trzeba by (modo potencial), trzeba byto (tiempo pasado), trzeba bytoby (potencial compuesto).

Conforme a la clasificación gramatical de los verbos polacos, realizada por Zygmunt Saloni ${ }^{2}$ y también por Saloni y Świdziński ${ }^{3}$, trzeba pertenece al grupo de los llamados verbos impropios (en polaco, czasowniki niewłaściwe).

${ }^{2}$ Z. Saloni, "Klasyfikacja gramatyczna leksemów polskich”, Język Polski, LIV, 1974, pp. 98-99.

${ }^{3}$ Z. Saloni, M. Świdziński, Składnia współczesnego języka polskiego, Warszawa, PWN, 2011, pp. 97-98. 
Entre los verbos polacos, dentro de la clase de los lexemas conjugados por tiempos y modos existen dos grupos, destacados según la presencia o ausencia de la categoría de persona. Por un lado, hay verbos conjugados por persona que se denominan lexemas verbales propios o verbos propios. Por otro lado, en polaco funcionan verbos que no están sujetos a la categoría flexiva de persona. Son verbos impropios (lexemas verbales impropios) de tipo wolno (se puede), warto (vale la pena), brakować (hace falta), świtać (amanecer) que no denotan al autor de la acción.

Trzeba, catalogado como el llamado verbo impropio, no cumple todos los criterios del verbo, pero tiene la capacidad de predicar y desempeña la función de predicado. Por tener un origen no verbal sino nominal (como los lexemas można, dość), por consiguiente, por no disponer de categorías flexivas típicas de un verbo, ha de emplearse con los exponentes de tiempo y modo ${ }^{4}$.

Respecto a las unidades de tipo można, trzeba, należy, Roman Laskowski ${ }^{5}$ propone la denominación predykatywy (una clase funcional de verbos que incluye lexemas de origen no verbal). Como el equivalente de los predykatywy para las necesidades de este artículo proponemos el término lexemas predicativos.

El lexema predicativo trzeba forma oraciones impersonales, sin sujeto, llamadas oraciones no nominativas, es decir, sin sujeto en el primer caso gramatical, el nominativo (zdania bezmianownikowe). Son esquemas basados en verbos impropios que denotan acciones en las cuales no es posible señalar algún agente ${ }^{6}$. Se trata de lexemas que designan fenómenos naturales, fisiológicos o expresan algún juicio de valor. Aparte de trzeba, las oraciones no nominativas se forman con unidades como należy (es necesario), warto (merece, vale la pena), wolno (se puede), wypada (conviene), można (se puede). A través de estos lexemas el hablante expresa un juicio, una evaluación del evento, pero se trata de una evaluación u opinión general. Las oraciones impersonales de este tipo no contienen información explícita sobre la opinión del sujeto hablante. Según la misma autora ${ }^{7}$, la expresión de un juicio general es una de las funciones principales de los verbos no flexivos.

\section{Trzeba en diccionarios bilingües}

El Gran dicconario polaco-español distingue dos significaciones de trze$b a^{8}$. El lexema está marcado con el cuantificador impers. y tiene los siguien-

${ }^{4}$ Ibidem, p. 97.

5 R. Laskowski, “Części mowy - problem syntaktyczny czy morfologiczny”, Acta Universitatis Lodzensis, Folia Linguistica, 2, 1981, pp. 117-131.

${ }^{6}$ R. Grzegorczykowa, Wyktady z polskiej sktadni, Warszawa, PWN, 2012, pp. 61-62.

${ }^{7}$ Ibidem, p. 62.

${ }^{8}$ O. Perlin, Wielki stownik polsko-hiszpański, Warszawa, Wiedza Powszechna, 2006. 
tes equivalentes: hay que, es preciso, es menester, se debe. La expresión jak trzeba citada en la frase zrobić (coś) jak trzeba recibe la siguiente traducción: hacer como es debido (como se debe). La frase trzeba ci wiedzieć tiene el equivalente 'debes saber', mientras que napisać gdzie trzeba se traduce como 'escribir donde es (sea) necesario'. En la entrada aparece también la expresión trzeba było go styszeć con el valor exclamativo, expresivo, traducida como ¡había que oírle! Siguiendo el esquema de los diccionarios de lengua polaca, el diccionario registra otra acepción, de ser algo necesario. Aparecen giros impersonales como hace falta, es necesario, es menester, se necesita, hay que. Se ofrecen dos ejemplos: Trzeba mieć dużo cierpliwości - Hace falta tener mucha paciencia y Trzeba mu wypoczynku - Necesita descansar (en el segundo caso se emplea en polaco el lexema sin verbo en infinitivo). La fórmula de réplica a la propuesta de ayuda Pomóc ci? Nie trzeba que antes hemos traducido como ¿Te ayudo? No hace falta, tiene en el diccionario la forma ¿Ayudarte? No es necesario. Como se puede observar, a un lexema en polaco le corresponden nueve formas en castellano.

Los otros diccionarios de español-polaco (el diccionario manual de la editorial Wiedza Powszechna o el diccionario de Langenscheidt) tienen como coautor a Oscar Perlin, el autor del Gran diccionario ya citado, por lo cual no los incluimos en este estudio. Quisiéramos comentar la entrada de trzeba en el Powszechny słownik hiszpańsko-polski, polsko hiszpański (2012) que ofrece tres equivalentes: es preciso, es necesario, hace falta y, para ampliar el panorama lexicográfico, nos gustaría añadir las propuestas de los diccionarios en línea. El diccionario Pons describe trzeba como verbo impersonal y no flexivo (a diferencia del Gran diccionario de Perlin en el cual trzeba recibe la cualificación impers. y no v. impers.) y distingue sus dos designaciones. La primera está marcada como 'ser indispensable' y le corresponden las construcciones hay que (con el ejemplo hay que trabajar), se debe y faltar. Se cita el ejemplo les falta silencio y calma. El diccionario ofrece la segunda acepción de trzeba que explica con el verbo należy y con el ejemplo de należy się postarać - se debe hacer un esfuerzo. También se registra la expresión fija jak trzeba usada en la frase zachowywać się jak trzeba, traducida por comportarse correctamente . $^{9}$

El diccionario en línea ling.pl contiene ejemplos diferentes a los citados. Propone dos significaciones (como las otras fuentes), la primera de należy con expresiones como hay que, es necesario, es preciso. Ofrece los ejemplos nie wiele [sic!] mu trzeba do śmiechu - no necesita mucho para reirse, trzeba to było zrobić - hubo que [fue necesario] hacerlo. Aparece otra acepción de ser necesario con la propuesta de hace falta y con el ejemplo concreto trzeba na to dużo pieniędzy - para eso hace falta mucho dinero ${ }^{10}$ ).

${ }^{9}$ PONS - Darmowy stownik języków obcych, <http://pl.pons.com/t\% $\% 5 \% 82$ umaczenie?q=trzeba\&l=espl\&in=\&lf=pl $>27$ de febrero de 2016.

${ }^{10}$ Ling.pl: Stownik internetowy w 7 językach, $<$ http://ling.pl/slownik/polsko-hiszpa\%C5\%84ski/trzeba $>27$ de febrero de 2016. 


\section{Las equivalencias traductológicas de trzeba}

En las fuentes examinadas hemos detectado 127 ocurrencias del lexema predicativo trzeba. Lo que llama la atención es una gran variedad de sus traducciones al castellano. Los ejemplos que hemos localizado se pueden dividir en dos grupos: construcciones impersonales y estructuras personales (con perífrasis tener que, deber, muy raramente el verbo necesitar).

Entre las construcciones impersonales destaca la perífrasis hay que, con 58 usos. A continuación, se ha detectado (no) hace falta con 13 empleos. Son mucho menos frecuentes los giros unipersonales, que aparecen esporádicamente, como es necesario y es preciso ( 3 empleos cada uno), lo mejor es y resulta indispensable (con un solo uso cada uno). Otras traducciones son puntuales (por ejemplo, una vez se ha registrado la construcción de haber + participio: Pues haberse quedado en la cama). En el grupo de las estructuras personales, hemos encontrado 16 ocurrencias de deber más infinitivo y 10 de tener que con infinitivo. Cabe señalar que la diferencia entre el número de los equivalentes es mínima, por lo cual no queremos formular juicios definitivos acerca de las tendencias o preferencias visibles en la traducción; sin embargo, como hemos comprobado en otras ocasiones, el examen de una cantidad más elevada de textos no cambia la imagen final y no ofrece mejores resultados: en las traducciones se producen procedimientos repetidos y la inclusión de un mayor número de fuentes del corpus no conlleva al resultado más amplio.

\subsection{La construcción hay que + infinitivo}

Las traducciones más frecuentes del lexema trzeba se han realizado mediante la perífrasis haber que + infinitivo:

1. Przecież trzeba myśleć historycznie, myśleć pamięcią narodu. (BS: 244) $)^{11}$

Yo creo que hay que pensar históricamente, pensar con la memoria del pueblo. (p. 202)

La construcción haber que + infinitivo es impersonal, tiene el 'sujeto cero' que parece imponer el verbo haber ${ }^{12}$. Leonardo Gómez Torrego denomina el carácter de esta perífrasis 'encubridor de actor' que puede ser agente o paciente y que puede ser aportado por un verbo en infinitivo, capaz de llevar un sujeto animado semánticamente como, por ejemplo, trabajar, sufrir, escri$b i r$, etc. En polaco, al igual que en español, trzeba exige un verbo en infinitivo

11 Para señalar el libro del que proviene la cita vamos a usar las siguientes siglas: ME Memorias encontradas en una bañera, PA - Un pequeño Apocalipsis, BS - La bella señora Seidenman, FM - Fin del mundo en Breslau.

${ }^{12}$ L. Gómez Torrego, "Los verbos auxiliares. Las perífrasis verbales de infinitivo", en: I. Bosque, V. Demonte (eds.), Gramática descriptiva de la lengua española, Madrid, Espasa Calpe, 2000, p. 3357. 
que implique a un autor de la acción (resultan imposibles las combinaciones con verbos impersonales padać - llover, wydarzyć się - ocurrir).

La construcción tiene el valor modal deóntico (obligativo, de gr. deón, obligación) o de necesidad. Podríamos afirmar que en los ejemplos citados estamos ante una traducción fiel a nivel morfológico y semántico, una equivalencia plena (con la pequeña diferencia estructural de falta de conector en polaco), en la que el hablante presenta un juicio de valor sin expresar explícitamente su opinión. Lo vemos también en el caso siguiente:

2. - Ile trzeba wygrać, by otrzymać nagrodę dodatkową? (FM: 201)

- ¿Cuánto hay que ganar para obtener el premio complementario? (p. 149)

En el original y en su traducción se nota una correspondencia clara entre ambos idiomas. En polaco, la expresión de un juicio general (a través del lexema impersonal trzeba) es una de las funciones principales de los verbos no flexivos. La construcción con trzeba, igualmente que la perífrasis hay que + infinitivo, encubre a la persona del interlocutor; de este modo, la orden o el consejo se expresan de manera más general.

Aunque hay que tiene carácter impersonal sintáctico y semántico, se emplea en ocasiones con una finalidad conativa. El hablante quiere actuar sobre la voluntad del interlocutor ${ }^{13}$. En nuestra opinión, este valor aparece en las siguientes oraciones:

3. - Trzeba coś zjeść. Żeby mieć siłę. (PA: 106)

- Hay que comer algo. Para tener fuerzas. (p. 100)

4. - Niech pan się wygodniej położy - odezwałem się do Kobiałki. [...] Trzeba się oszczędzać. (PA: 107)

- Tiéndase más cómodamente -dije a Kobialka. [...] Hay que cuidarse. (p. 119)

En suma, el valor fundamental de haber que + infinitivo refleja perfectamente el significado de trzeba + infinitivo: ambas construcciones denotan obligación, necesidad y conveniencia. En las dos se anuncia que es necesario, es obligado hacer algo, sin señalar al autor de la acción.

En ocasiones, en las novelas aparecen las formas compuestas trzeba by y trzeba byto. La primera tiene una grafía interesante. A diferencia de otros verbos polacos se escribe por separado, por tratarse de una palabra que sí que funciona como predicado, pero tiene origen nominal. Las formas compuestas señaladas se trasladan al castellano a través del tiempo futuro hipotético (condicional simple) o el imperfecto de indicativo, respectivamente:

5. Myślę, że trzeba by sprawdzić te daty pod kątem znaczenia liczb. (FM: 165)

- Creo que habría que volver a analizar esas fechas en relación con el valor de las cifras. ${ }^{14}$

13 Ibidem, p. 3358.

${ }^{14}$ En el caso de las novelas Fin del mundo en Breslau y Memorias encontradas en una bañera, disponemos de las versiones electrónicas, por lo cual no podemos señalar los números de páginas. 
6. Jedyną skarbnicą wiedzy była pamięć żyjących fachowców, ją więc trzeba było utrwalić przede wszystkim. (ME: 8)

El único receptáculo de información era la memoria de los profesionales que entonces vivían; ante todo, pues, había que preservar esta información.

Estamos ante traducciones literales. En la primera, las formas verbales en ambos idiomas denotan necesidad de realizar un hecho posible en su realización futura. En la segunda, el hablante se refiere a una acción que era necesario realizar en el pasado no bien determinado. Asimismo, se mantiene la misma modalidad deóntica. En suma, en las novelas polacas las formas compuestas trzeba by, trzeba byto, trzeba by byto, trzeba będzie aparecen tan solo 15 veces en nuestro corpus. El uso reducido de este lexema en el tiempo futuro simple o futuro hipotético está, si se puede decir, justificado. Evidentemente, la forma presente trzeba tiene la perspectiva temporal prospectiva y las acciones que denota llevan marca de acciones que han de realizarse a partir del momento actual.

\subsection{La perífrasis deber + infinitivo}

Lo que llama la atención en el resultado de nuestro corpus de ejemplos es el hecho de que en varias ocasiones, la construcción impersonal, no nominativa, se traslada al castellano mediante estructuras personales, con verbos conjugados. La forma más frecuente es la perífrasis deber + infinitivo que se ha demostrado como equivalente del verbo impropio trzeba 16 veces. Resulta interesante que la impersonalidad de trzeba (usado para encubrir al hablante y con el fin de no expresar un juicio personal), con su carácter de una necesidad general, recibe en las traducciones una lectura personal:

7. Odłożyłem słuchawkę. Trzeba było się spieszyć. (PA: 224)

Colgué el auricular. Debía darme prisa. (p. 205)

El verbo deber combinado con el infinitivo denota la obligación. Los valores semánticos más frecuentes de esta perífrasis son los de obligación activa, de obligación pasiva o de necesidad. El valor de obligatoriedad de la perífrasis se desprende del propio carácter semántico del verbo deber. Asimismo, la estructura puede denotar la obligación derivada del deseo del hablante sobre la necesidad de realizar un hecho ${ }^{15}$. Aparte de estos valores, deber + infinitivo denota también probabilidad. Como en los textos polacos estamos ante la expresión de la obligación, necesidad o conveniencia, el valor de probabilidad no se manifiesta en las traducciones.

${ }^{15}$ L. García Fernández, Á. Carrasco Gutiérrez, Diccionario de perifrasis verbales, Madrid, Gredos, 2006, p.110. 
La perífrasis que corresponde a la forma presente de trzeba aparece en español en diferentes tiempos gramaticales:

8. Mówiła sobie, że trzeba tę twarz zapamiętać [...] (BS: 197)

Se decía a sí misma que debía retener los rasgos de aquel hombre [...] (p. 152)

En este caso el uso del tiempo imperfecto tiene su justificación evidente. En polaco es posible expresar una acción en el pasado mediante el tiempo presente e incluso futuro mientras que en castellano se requiere concordancia temporal. En el ejemplo siguiente

9. - Może trzeba zatelefonować gdzieś? [...]. (ME: 54)

- ¿No debería hacer una llamada telefónica? [...].

el futuro hipotético refleja adecuadamente la propuesta y la duda expresadas en polaco a través del marcador discursivo może (tal vez). En otro caso

10. - Myślałem, że wchodzę do restauracji. Pomyliłem się.

- To trzeba było wyjść. (PA: 129)

- Debía haber salido. (p. 120)

la forma trzeba byto que señala un evento pasado, la conveniencia de realizar algo ya imposible de llevarse a cabo se traslada a través del imperfecto de indicativo acompañado de un infinitivo compuesto. Tal forma expresa el deseo del protagonista sobre la necesidad de una acción que no se ha hecho y cuya realización ya no es posible (valor contrafactivo). La traducción se corresponde perfectamente con la idea expresada en polaco.

\subsection{La construcción tener que + infinitivo}

Entre otras expresiones de la necesidad referida a un hablante determinado, se emplea la construcción tener que + infinitivo. En estos casos, que ascienden a 10 ejemplos en el corpus, la expresión impersonal, con el sujeto cero, tiene un homólogo castellano personificado.

11. Trzeba tam być. Na Antonienstrasse. Ze wszystkimi ludźmi. (FM: 299)

Tengo que estar allí. En la Antonienstrasse. Con todos mis hombres.

Tener que + infinitivo es una perífrasis modal, gramaticalizada, con valor de necesidad. Puede tener más de una interpretación. A veces manifiesta la modalidad obligatoria o de necesidad ineludible; asimismo, puede expresar probabilidad. Quiere decir que en el marco de la modalidad deóntica, la necesidad es entendida como obligación, pero puede entenderse como un grado de certeza o probabilidad. La misma oración María ha tenido que adelgazar diez 
kilos ${ }^{16}$ puede recibir dos lecturas, una deóntica ('María se ha visto obligada a adelgazar'), otra, epistémica ('María probablemente ha adelgazado diez Kg').

El rasgo de universalidad y generalidad contenido en el lexema predicativo trzeba a través del cual el hablante no pronuncia su opinión individual se puede observar en estos fragmentos:

12. - Niedaleko, pani Gosiu. Trzeba pójść w prawo [...]. (PA: 228)

- Por aquí cerca, señora Gosia. Tiene que ir a la derecha [...]. (p. 208)

13. - Nerwy - rzekł Müller. - Jutro będzie dobrze. Musi pani pójść do łóżka. Trzeba to przespać [...] (BS: 181)

- Son los nervios - dijo Müller -. Mañana todo estará algo mejor. Tiene que acostarse y dormir [...] (p. 135)

En sus versiones españolas, a diferencia de la expresión de la necesidad en polaco, el hablante se dirige de manera personal a su interlocutor. En nuestra opinión, se conserva el valor obligativo, puesto que la construcción perifrástica expresa una obligación externa, impuesta por alguna autoridad, es decir, normalmente por una institución, persona o norma ética o por las circunstancias externas.

La perífrasis tener que + infinitivo puede encerrar también los rasgos de deseo e intención. García Fernández y Carrasco Gutiérrez en el Diccionario de perifrasis verbales citan, a modo de ejemplo, la frase Tendría que levantarme y replicarle que anuncia un deseo sobre la necesidad de un hecho que no se ha cumplido ${ }^{17}$. Conforme a las consideraciones de Gómez Torrego ${ }^{18}$, la perífrasis examinada tiene también la modalidad que el autor denomina intencional (Tengo que contaros la última noticia). Si la actitud del hablante no está clara, es el aspecto pragmático (el contexto) o la entonación los elementos que pueden ayudarnos a descifrar la idea del mensaje. Consideramos que la siguiente oración, además de señalar la obligación, encierra la intención del hablante de cómo debería actuar:

14. Trzeba gwałtownie zerwać się z krzesła. Mówić dużo, głośno. (BS: 173)

Tengo que levantarme de la silla de un salto. Hablar mucho y a voces. (p. 128)

La estructura con el vocablo trzeba acompañado de infinitivo (al igual que haber que, deber + infinitivo), a diferencia de sus homólogos en español, no es una perífrasis verbal. En la lingüística polaca funciona el concepto de la perífrasis, pero se refiere a otro tipo de estructuras. Existe el término peryfraza que tiene dos variantes: poética y gramatical. En la sintaxis, peryfraza designa predicados como brać udziat (participar) o mieć nadzieję (tener esperanza). El concepto de peryfraza abarca también las formas analíticas de los tiem-

16 Ibidem, p. 260-261.

${ }^{17}$ Ibidem, p. 258.

${ }^{18}$ L. Gómez Torrego, Perífrasis verbales: Sintaxis, semántica y estilística, Madrid, Arco Libros, 1988, pp. 82-86. 
pos verbales, como las formas futuras de los verbos de aspecto imperfectivo będzie czytat o będzie czytać ${ }^{19}$.

Trzeba con infinitivo forma el predicado verbal (y no una perífrasis) y se estudia de dos maneras diferentes: como el predicado verbal compuesto o simple en que el verbo en infinitivo funciona como complemento directo.

\subsection{Traducciones mediante estructuras impersonales}

Lo que destaca en la equiparación de las unidades en español y en polaco es el hecho de que trzeba sufre muchas variedades en el proceso traductor. Observamos traslaciones bien distintas donde el carácter impersonal se refleja mediante giros unipersonales. En total, trzeba se ha traducido de forma impersonal 22 veces (salvo haber que + infinitivo). Se trata de expresiones hace falta, es necesario, es preciso $\mathrm{y}$, de otras dos que, aunque han aparecido solo una vez, nos parecen muy acertadas; son lo mejor sería que y resulta indispensable. A modo de ejemplo, presentamos un caso del empleo de es preciso que:

15. - Reklamacje załatwiane są przy stoliku. Tam trzeba było wezwać szefa - mruknął strażnik. (FM: 85)

- Las reclamaciones se resuelven en las propias mesas. Para pasar ahí, sería preciso llamar al jefe -gruñó el vigilante. (p. 62)

En este fragmento se emplea el lexema predicativo trzeba en el tiempo pasado. En la versión española observamos un cambio interesante de tiempo gramatical: aparece el giro unipersonal en el tiempo futuro hipotético, por tanto, no se refleja el hecho pasado, la frase tiene el carácter atemporal, en el sentido de una norma universal. Las traducciones de trzeba a través de los recursos impersonales conservan la idea de necesidad; lo que es llamativo son los cambios de tiempo gramatical. La forma presente tiene equivalentes expresados en el tiempo pasado, futuro o futuro hipotético.

La estructura que en los trasvases al castellano tiene más representación es (no) hace falta (13 usos):

16. $-[\ldots]$ nie znam, niestety, godności $[\ldots]$

- To nic, nie trzeba [...] (ME: 45)

- No importa, no hace falta [...]

17. Mam warsztat taki, co już nie trzeba panu opisywać (BS: 161)

No hace falta que le describa cómo es mi taller. (p. 116)

${ }^{19}$ S. Karolak, "Peryfraza”, en: Polański K. (ed.), Encyklopedia językoznawstwa ogólnego, Wrocław, Zakład Narodowy im. Ossolińskich, 1999, pp. 431-432. 
En las oraciones de este tipo con hace falta se transmite el sentido de la expresión nie trzeba. Es una forma de cortesía, usada en el coloquio para responder a la propuesta de ayuda, auxilio o servicio de parte del interlocutor:

18. - Zadzwonić po lekarza?

- Nie trzeba. Już dobrze. (PA: 22)

- ¿Quieres que llame al médico?

- No hace falta. Ya estoy bien. (p. 25)

Aparte de la combinatoria de trzeba con un infinitivo, el lexema forma estructuras nominales, de tipo mnie trzeba duszy przyjaznej (necesito un alma amiga) y no tiene, por tanto, valores modales. Se traduce, en cada caso, de manera distinta y es imposible indicar una norma o una tendencia en su trasvase al español.

Todas las traducciones que hemos estudiado son interesantes y lamentamos no poder comentar más ejemplos de cómo se traslada el significado de necesidad al castellano. Aparte de las equivalencias comentadas, en las traducciones se dan elisiones del lexema trzeba, los cambios de punto de vista (de la perspectiva, de la modalidad) y productos de la creación discursiva de parte de los traductores en los que se modifica de manera considerable la idea original y se usan otros recursos léxicos.

\section{Observaciones finales}

En la mayoría de los ejemplos del material examinado, las equivalencias traductoras más repetidas tienen carácter impersonal, por tanto, mantienen el valor de trzeba que es de expresar necesidad sin pronunciar un juicio personal. La forma más usada es la construcción haber que + infinitivo que corresponde altamente a los valores semánticos del vocablo trzeba. Luego, se observan traducciones mediante giros unipersonales bien variados. Sorprendentemente, hemos detectado el empleo de verbos personales, flexivos, como deber o tener que acompañados de infinitivo. El valor encubridor del lexema trzeba, que expresa necesidad de forma universal y general sin señalar al posible actor de un hecho, recibe una lectura directa con la indicación del mismo sujeto hablante o de su interlocutor o interlocutores como actores de las acciones.

El método de estudio por el cual hemos optado, que es de carácter inductivo, nos ha permitido partir de los datos, es decir, usos de los lexemas en el contexto, para luego formular observaciones acerca de las normas de traducción y funcionamiento de las equivalencias. No obstante, este método de estudio tiene sus puntos débiles: puede que hayamos obtenido resultados incompletos debidos, entre otros, a la tendencia individual de los traductores, a las modas de traducir, a las decisiones de los editores, etc. Por ello, hemos 
limitado nuestras afirmaciones sobre los equivalentes tan solo a la traducción y no a la lengua en general en todas sus modalidades.

Por lo que se refiere a la comparación de los resultados de este análisis con los diccionarios bilingües, se observa que los equivalentes de traducción se corresponden parcialmente con las propuestas lexicográficas. Trzeba se traduce como hay que, es preciso, hace falta, es necesario, lo cual es idéntico con las entradas presentes en los diccionarios. Otras equivalencias que proponen de es menester, se debe, se necesita no han aparecido ni una vez en las traducciones. En cambio, las traslaciones a través de las perífrasis modales (deber, tener que) no se registran en ninguno de los diccionarios revisados.

\section{Referencias bibliográficas}

\section{Fuentes del corpus}

KONWICKI T.

1987 Un pequeño apocalipsis, trad. Bożena Zaboklicka, Francesc Miravitlles, Barcelona, Muchnik Editores.

1994 [1979] Mała apokalipsa, Warszawa, Niezależna Oficyna Wydawnicza.

KRAJEWSKI M.

2005 [2003] Koniec świata w Breslau, Warszawa, Wydawnictwo WAB.

2008 Fin del mundo en Breslau, trad. Fernando Otero Macías, Madrid, Alamut.

LEM S.

1977 Memorias encontradas en una bañera, trad. Jadwiga Maurizio, Barcelona, Bruguera (Ediciones B).

2009 [1961] Pamiętnik znaleziony w wannie, Dzieła, t. XIII, Warszawa, Biblioteka Gazety Wyborczej.

SZCZYPIORSKI A.

1999 [1986] Początek, Poznań, Wydawnictwo Sens.

2002 La bella señora Seidenman: el comienzo, trad. Pilar Gil Cánovas, Barcelona, El Aleph Editores.

\section{Obras de consulta}

BAŃKO M.

2000 Inny słownik języka polskiego, Warszawa, Wydawnictwo Naukowe PWN.

GARCÍA FERNÁNDEZ L., CARRASCO GUTIÉRREZ Á. (eds.)

2006 Diccionario de perifrasis verbales, Madrid, Gredos.

GÓMEZ TORREGO L.

1988 Perifrasis verbales: Sintaxis, semántica y estilística, Madrid, Arco Libros.

2000 "Los verbos auxiliares. Las perífrasis verbales de infinitivo", en: Bosque I., Demonte V. (eds.), Gramática descriptiva de la lengua española, Madrid, Espasa Calpe. 
GRZEGORCZYKOWA R.

2012 Wyktady z polskiej sktadni, Warszawa, PWN.

\section{KAROLAK S.}

1999 [1993] "Peryfraza", en: Polański K. (ed.), Encyklopedia językoznawstwa ogólnego, Wrocław, Zakład Narodowy im. Ossolińskich, pp. 431-432.

\section{LASKOWSKI R.}

1981 "Części mowy - problem syntaktyczny czy morfologiczny", Acta Universitatis Lodzensis, Folia Linguistica, 2, pp. 117-131.

MARTÍ MARCA A., MARTÍ MARCA J., JARDEL B.

2012 Powszechny stownik hiszpańsko-polski, polsko-hiszpański, Warszawa, Wiedza Powszechna. PERLIN O.

2006 [2002] Wielki słownik polsko-hiszpański, Warszawa, Wiedza Powszechna.

SALONI Z.

1974 "Klasyfikacja gramatyczna leksemów polskich”, Język Polski, LIV, pp. 3-13 y 93-101. SALONI Z., ŚWIDZIŃSKI M.

2011 [1985] Sktadnia wspótczesnego języka polskiego, Warszawa, PWN. SZYMCZAK M. (ed.)

1998 Stownik języka polskiego, t. 1-3, Warszawa, PWN.

\section{Páginas web}

Ling.pl: Stownik internetowy w 7 językach, <http://ling.pl/slownik/polsko-hiszpa\%C5\%84ski/trzeba> 27 de febrero de 2016.

PONS - Darmowy słownik języków obcych, <http://pl.pons.com/t\%C5\%82umaczenie?q=trzeba\&l $=$ espl\&in $=\& l f=p l>27$ de febrero de 2016.

\section{Aspects of translation of the Polish verb trzeba into Spanish} Spanish.

Keywords: translation - equivalents — contrast - expressing necessity — Polish and

\section{Abstract}

The main purpose of this study is to analyze the Polish impersonal verb trzeba (one must) and to compare it with corresponding Spanish equivalents. We examine this verb in terms of translation study: we search for this Polish lexeme in the original texts (Polish novels of prominent writers), then we search for its equivalents in translation and describe them with the objective to present some comparative observations. We try to analyze the expression of necessity in both languages and semantic values of the lexeme trzeba since it has an interesting structure and use and is considered a problematic verb. 